\title{
A Review on Grid Connected Converter for Single Phase Transformerless PV Systems
}

\author{
Sonal C. Waychol ${ }^{1}$, Dr. P. J. Shah ${ }^{2}$ \\ ${ }^{1}$ ME Scholar, Department of Electrical Engineering SSBT COET, Jalgaon, India, 425001, \\ ${ }^{2}$ Professor, Electronics \& Telecommunication Engineering Department, SSBT COET, Jalgaon, India, 425001
}

Received on: 16 July, 2021

Revised on: 17August, 2021

Published on: 19 August, 2021

\begin{abstract}
Renewable energy has become a central point of interest as an alternative source of energy to the customary fossil fuel and other energy resources due to the fact that it is more environmentally friendly, abundant and economically possible. Solar photovoltaic systems have become one of the fastest growing renewable energy sources that can be integrated into the grid distribution network. Here we study, the recent development of grid-connected $P V(G P V)$ generation systems comprising of quite a few sub-components as $P V$ modules, DC-DC converter, maximum power point tracking (MPPT) technique, and an inverter.

Single phase transformerless inverters are commonly being used for small scale grid connected PV systems due to their high efficiency, lower cost and high-power density. Though, leakage current is the main concern in these inverters which needs to be addressed carefully. Besides, PV inverters should also be capable of injecting a definite amount of reactive power into the grid as prescribed by the international regulations. Due to the advantages of achieving high performance and low cost, transformerless inverters are commonly used in grid-tied Photovoltaic $(P V)$ generating systems. Higher efficiency designing an effective solar inverter and also monitoring the power the inverter injects into the standalone device. A number of transformerless inverter topologies, are studied to satisfy the safety criteria of leakage currents.
\end{abstract}

Keywords- photovoltaic (PV) systems, pulse width modulation (PWM) inverters, Leakage current, multilevel systems.

\section{I - INTRODUCTION}

A world population increases, standard of living also increases, which further results in increase of demand for commercial energy. Energy is the elementary factor of the expansion of industrialization, a criterion for social development and its accessibility, as well as the pattern of consumption, plays an important role in sustainable expansion. Meeting energy demands pose a challenge to the utility planners and policymakers on managing this dispute as it could result in difficulties for energy security, and $\mathrm{CO} 2$ emission diminutions, air protection [1].

It has been very clear from recent studies and documentations that fossil fuels would last only a few more decades. The cost of fossil fuel has become a foremost challenge for all of human kind. Not only the economic value but the environmental impacts of fossil fuels have clearly made us move toward substitutes. The greatest substitutes that can really make a difference for sustainability, such as reducing green-house gases and long-term economics, are the renewable energy sources.

Renewable Energy term is derived from a wide range of resources all of which are based on self-renewingenergy sources such as sunlight, flowing water, wind, the earth's internal heat and biomass embraced of energy crops, agricultural, industrial and municipal waste. Renewable energy sources generate little if any greenhouse gases, waste, or pollutants that contribute to acid rain, urban smog, and health problems and do not have need of an environmental clean-up charge. In addition, these resourcescan be used to yield electricity for all economic sectors, fuels for transportation, heat for building and industrial processes.

Among all the various RE technologies, solar photovoltaic or precisely $\mathrm{PV}$ is the most exploited RE 


\section{International Journal of Innovations in Engineering and Science, www.ijies.net}

source alongside with hydro and wind power in terms of the pace of deployments and due to the amply of sunlight over a large area of the earth surface it is considered a very capable source of future electrical power generation thus giving rise to several applications of Photovoltaic system. It also offers continuous cost saving over the years, a stable system, fast technological progress, being maintenance and pollution-free. There are two categories of the solar energy system, namely stand-alone and gridconnected PV (GPV) generation systems. Both systems have several similarities and differences in their applications and purposes. By general definition, a stand-alone PV system generates power independently of the grid and a GPV system is a self-regulating decentralized power system that is connected to an electricity transmission and distribution system [2].

\section{II - LITERATURE REVIEW}

Grid Connected Solar PV System: The PV system connected to the grid requires two distinct tasks one of which is to confirmthat the solar panels are operated at MPP and the other is that the injected current must be sinusoidal. Grid connected PV system feed the solar energy directly into the building loads without battery storage.

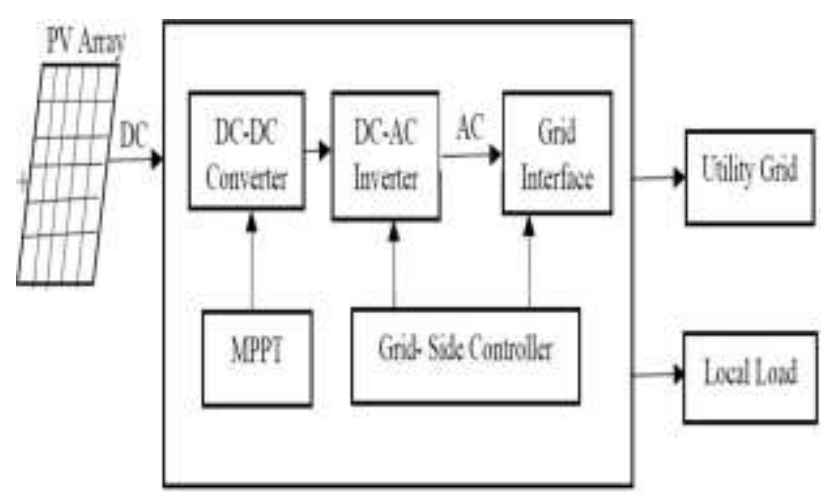

Fig 1-Block diagram of grid connected PV System

The grid-connected PV system consists of PV array, DCDC converter, DC-ACinverter, MPPT, controller, grid. In grid connected PV system the energy is produced from the solar Panel is nothing but the DC source in order to take part with the grid it is converted into AC by using an inverter. The voltage produced from the solar panel is not constant because of the varying climatic condition, but in order to produce the maximum power, Maximum Power Point Tracking (MPPT) controller is used here. An anti-islanding circuitry is provided to disconnect the utility from the grid in case of black out, which ensures the safety of the utility workers [3].

Here are its features:

- This is the economical mode of going solar.

- You will still be dependent on the grid.

- On an average, up to $20 \%$ of your energy needsmight still be satisfied by the grid.

- Your dependence on the grid rules out the uncertainties and disadvantages associated with going solar on its own.

- You don't have to worry about whether or not your system is producing adequate energy; this is very crucial as solar power is heavily depending on weather and availability of sunlight (and thus can't be generated during the night).

- The surplus power your system generates would be supplied to the grid, earning you credits for the times you extract power from the grid [4].

Maximum Power Point Tracking: The Maximum Power Point Tracker (MPPT) is needed to optimize the amount of power obtained from the photovoltaic array to the power supply. The output of a solar module is categorized by a performance curve of voltage versus current, called the I-V curve. The maximum power point of a solar module is the point in the I-V curve that resembles to the maximum output power possible for the module. This value can be determined by finding the maximum area under the current versus voltage curve Figure. 2 [5].

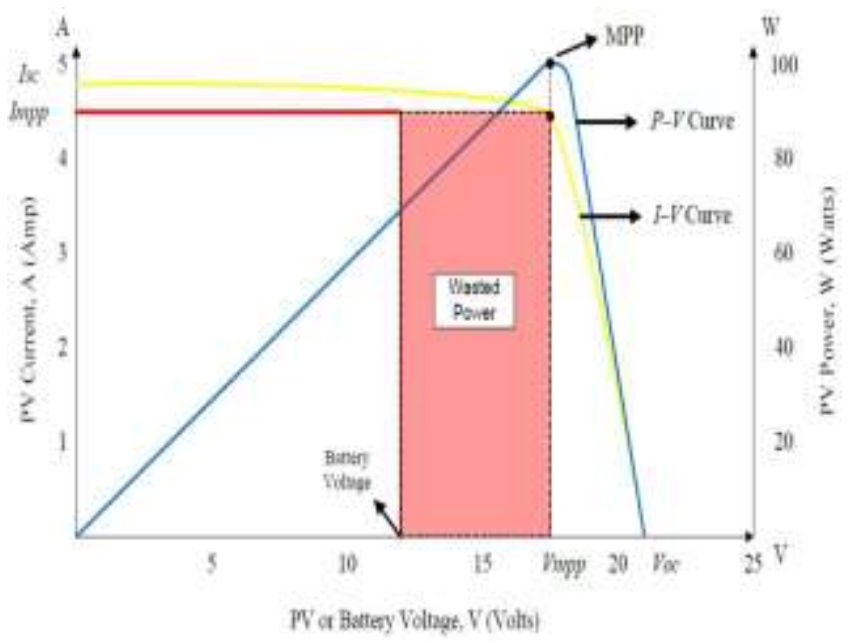

Fig 2 - PV array battery charging power transfer graph

Suppose that when a conventional PV module connects in a straight line to the battery, it will force the module to operate at battery's voltage level of $12 \mathrm{~V}$ which is not a flawless operating voltage level for the available maximum power that a PV module is efficient of generating. Therefore, there is a portion of power that 


\section{International Journal of Innovations in Engineering and Science, www.ijies.net}

could not be pull out from the module and it is wasted power. The implementation of MPPT will vary the electrical operating point of the PV module so that the module is capable to provide the maximum available power at the optimal value (maximum power point, MPP) of its voltage and current rated level [6]. There are different methods to track down the maximum power point, a few of which are listed below [7]:

- Perturb and Observe method

- Incremental Conductance method

- Parasitic Capacitance method

- Constant Voltage method

- Constant Current method

Grid Tied PV Inverter: Novel inverter system designs are being established, in order to realize cost-efficient PV systems. An overall classification of grid connected PV inverters is comprised of central inverters, string inverters, multistring inverters and Ac modules inverter.

1) Central inverter $(20-100 \mathrm{~kW})$ :

In centralized inverter topology, the PV modules are divided into series connections (called string), each generating a sufficiently high voltage to avoid further amplification. These series connections are then linked in parallel, by using string diodes, to reach high power around $10 \mathrm{~kW}$ and $250 \mathrm{~kW}$. Central inverter arrangement is shown in Fig.3 (a).

Disadvantages of centralized inverters are:

- There is high voltage dc cable between the PV modules and the inverter.

- More power loss is there due to a centralized MPPT, mismatch losses between the PV modules, losses in the string diodes.

- Non flexible design in large production PV plants.

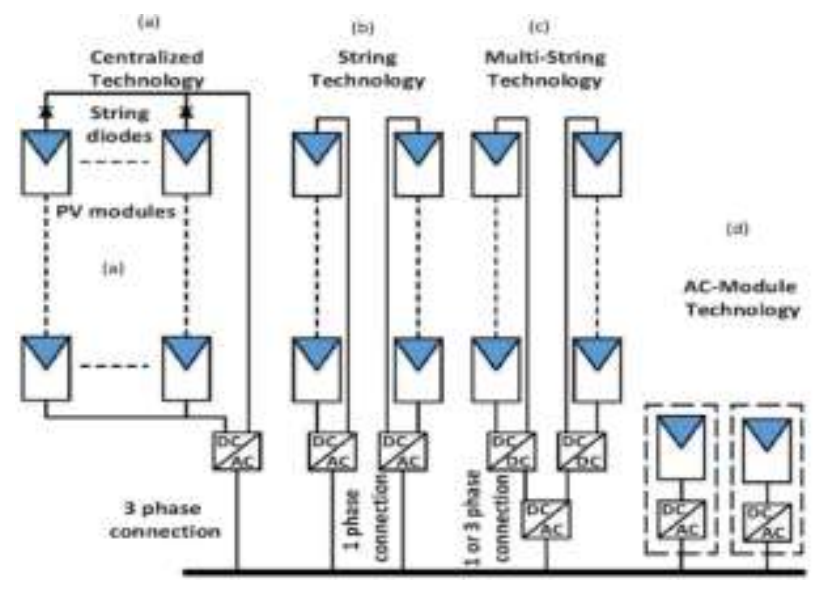

Fig 3-Grid connected PV inverters types
2) String Inverters $(1-8 \mathrm{~kW})$ :

The string inverters are reduced variety of the centralized inverter, where a single string of PV modules is connected to the inverter. The input voltage may be high enough to avoid voltage strengthening. There are no losses associated with string diodes and separate MPPTs which results in the increase of the overall efficiency compared to the centralized inverter, and the reduction in the price, due to mass production. String inverter configuration is shown in Fig. 3(b).

3) Multi-String Inverters $(8-20 \mathrm{~kW})$ :

In multi string formation, several strings are interfaced with their own dc-dc converter to a common dc-ac inverter. The profit of this configuration is that each string can be controlled individually. Multi-string inverter configuration is shown in Fig. 3(c).

4) AC Modules (150-600 W):

The ac modules integrate each PV panel and the inverter into one electrical device. It eradicates the mismatch loss between PV modules, since there is only one PV module.

This configuration increases the possibility of large integration. AC modules are superlative for installations where one or more panels may be shaded, or where panels are facing diverse directions. A system that uses ac modules will produce more power than a similar system with a string inverter, however, they are more expensive than string inverters. AC module configuration is shown in Fig. 3(d) [8], [9].

\section{III -METHODOLOGY}

Various inverter topologies: Based on the configuration and types of components used, inverters can be classified into different categories. This partition of categories is based on various factors, such as, number of power processing stages i.e., single stage and multistage, transformer and transformerless configurations, number of levels involved in the design and the type of switching used. Each category is briefly described as follows:

\section{1) Inverters based on number of power processing} stages:

The inverters based on the power processing stages are classified into two main types, whichare the single stage inverters and the multiple stage inverters, [10] as presented in Fig. 4. 


\section{International Journal of Innovations in Engineering and Science, www.ijies.net}

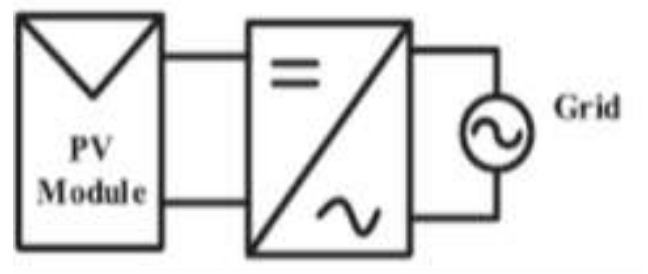

(a) Single stage inverter

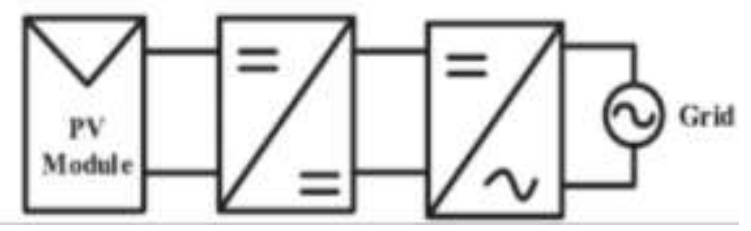

(b)Two stage inverter

Fig 4- Inverters based on number of power processing stages

\section{2) Inverters based on the existence or absence of the} transformer:

In general, on the basis of transformer the grid connected PV inverter topologies are categorized into two, i.e., those with transformer and transformerless.

\section{Transformerless inverter topologies:}

Inverters can have one or more stages according to the levels of power conversion. Generally singlephase systems are most commonly used in private sector or residential application. The majority of such PV systems can have up to $5 \mathrm{~kW}$ and are roof mounted with a fixed tilt and southward orientation. Taking into concern the presented circumstances, highly efficient single phase inverter topologies that will most likely reach a high level of efficiency at low cost are the ones well-known by a single phase transformerless inverters [11].

Here is the detailed classification of various inverter topologies [12]:

a) Zero state Decoupled Topologies:

- H5 topology

- Heric Topology

- Improved H6 Topology

b) Zero state mid-point clamped topologies:

- H6 topology

- HB-ZVR (High bridge zero voltage rectifier)

- PN-NPC (Neutral point clamped)

c) Solidity clamped topologies:

- NPC Topology

- Dual parallel buck topology

3) Inverters based on the number of levels involved in the design:
In comparison to the simple two-level inverters, multilevel grid-connected inverters offer number of benefits. The multilevel inverters result in the AC voltage at the inverter's output terminal, which comprises of several staircase voltage levels. The staircase sinusoidal waveform resulting from the multilevel inverter is near to an actual and pure sinusoidal wave with low total harmonic distortion. Thus, the filter requirement is reduced and the harmonic distortion is low. Various DC voltage levels can be easily formed due to the modular structure of PV arrays; therefore, multilevel topologies are chiefly suitable for the PV systems [13], [14].

Some multilevel inverter topologies are:

- Half-bridge diode clamped inverters

- Full-bridge single leg clamped inverters

- Cascaded inverters

4) Inverters based on the type of switching employed:

In general, there exist two types, the hard and soft switching inverters. Thus, both hard and soft switching inverters can be comprising of one or more than one power stages [15]. Nowadays, the gridconnected PV inverters are designed using the soft switching technique in order to complete high power density, high efficiency, and better performance. Serious EMI problems and switching losses are caused by unexpected variation in switch currents and voltages, especiallyin the high-frequency switching inverter. This abrupt switching of the devices at a random instance is referred to as the hard switching and thus, causes various problems in the switchingprocess [16].

\section{IV - CONCLUSION AND FUTURE WORK}

RESs offer methods for generating electricity with minimal environmental impacts. However, because of their high integration levels, various standards, rules, and requirements have been issued for ensuring stable and secure operation of the PV system. The PV market has practiced in the last decade an exponential growth, becoming an important alternative and clean energy source in many countries. Along with the reduction in price and the increase in efficiency of the PV modules, the PV converter topologies have been continuously varying, following more demanding requirements and standards. These regulations are being improvedto a new power system scenario where renewable energy sources are an important part of the energy mix. This review explored the current trend of renewable power sources 


\section{International Journal of Innovations in Engineering and Science, www.ijies.net}

around the globe and investigated and compared the innumerable recent requirements and standards with respect to the integration of RESs into the grid for ensuring grid stability.

Transformerless PV grid-connected inverters for residential applications are the deviceson the market with the fastest growth and development. Transformerless inverters offer better efficiency, compared to those inverters that have galvanic isolation. But in case the transformer is omitted, the generated common mode behavior of the inverter topology greatly impacts the ground leakage current through the parasitic capacitance of the PV array. This paper has reviewed the different transformerless PV inverter topologies presently available.

These days, meeting these legal requirements, PV inverter topologies deal with issues such as high efficiency, high power density, grid code compliance, reliability, long warranties and economic expenses. A good number of PV inverter topologies can be found in the market for string, multistring central and ac-module PV applications. For further study we will be using gridconnected transformerless PV converter based on a CFB topology with two full bridges, out of which one is supplied by a flying capacitor.

In future, it is expected that overall performance of the grid-connected solar PV system will be improved and the cost will be minimized. According to the precise power requirements, location, and capacity for grid connection, this review study will help the engineers in picking the most suitable and appropriate control technique and inverter topology. It is also expected that this survey will be advantageous to the engineers, researchers, manufacturers, and users working in the field of solar energy for enhancing the binding of solarenergy and its grid integration. In addition, it will also help them in selecting appropriate topology for their particular application.

\section{REFERENCES}

[1] Mohsen Shayestegan, Mohammad Shakeri, Hamza Abunima, S.M. Salim Reza, M. Akhtaruzzaman, Badariah Bais, Sohif Mat, Kamaruzzaman Sopian, Nowshad Amin "An overview on prospects of new generation single-phase transformerless inverters for grid-connected photovoltaic (PV) systems" Elsevier (2017) Renewable and Sustainable Energy Reviews 82 (2018) 515-530.

[2] Ariya Sangwongwanich, Yongheng Yang, Dezso Sera, Hamid Soltani, and Frede Blaabjerg, "Analysis and Modeling of Interharmonics from Grid-Connected Photovoltaic Systems" IEEE Transactions on Power
Electronics, Vol. Pp, No. 99, 2017

[3] Rasedul Hasan, Saad Mekhilef, Mehdi Seyedmahmoudian, BenHoran "Grid-connected isolated PV microinverters: A review" Elsevier (2017) Renewable and Sustainable Energy Reviews 67(2017)1065-1080

[4] Muhammad Hafeez Mohamed Hariri, Mohd Khairunaz Mat Desa, Syafrudin Masri and Muhammad Ammirrul Atiqi Mohd Zainuri, "Grid-Connected PV Generation System-Components and Challenges: A Review” MDPI Energies 2020, 13, 4279.

[5] Ali Q. Al-Shetwi, M.A. Hannan, Ker Pin Jern, M. Mansur, T.M.I. Mahlia "Grid- connected renewable energy sources: Review of the recent integration requirements andcontrol methods" Elsevier (2019) Journal of Cleaner Production 253 (2020)

[6] Arash Anzalchi, Arif Sarwat, "Overview of technical specifications for grid-connected photovoltaic systems" Elsevier (2017) Energy Conversion and Management 152 (2017)312-327

[7] K.Arulkumar, K.Palanisamy , D.Vijayakumar School of Electrical Engineering, VIT University, Vellore "Recent Advances and Control Techniques in Grid Connected PV System - A Review” International Journal Of Renewable Energy Research, Vol.6, No.3, 2016

[8] Patrao Herrero, I.; Figueres Amoros, E.; Gonzalez Espin, FJ.; Gabriel Garcera. "Transformerless Topologies for Grid-Connected Single-Phase Photovoltaic Inverters". Renewable and Sustainable Energy Reviews. (2011) I Vol 15, Issue 7, (07/2011)]

[9] B Loveswara Rao, D Swathi, P Viswa Teja, V Sai Pranay, "A Transformerless Grid Connected to PV System Based on Heric Inverter" Journal of Critical Reviews ISSN-2394-5125 Vol 7, Issue 9, 2020

[10] Qing Meng, Tianye Liu, Chengxin Su, Huifang Niu, Zhuo Hou, Noradin Ghadimi, "A Single-Phase Transformer-Less Grid-Tied Inverter Based on Switched Capacitor for PV Application" Journal of Control, Automation and Electrical Systems (2019)

[11] Jinhong Liu, Lin Zhou, Bin Li, Chen Zheng and Bao Xie, "Modeling and Analysis of a Digitally Controlled Grid-Connected Large-Scale Centralized PV System" IEEE Transactions on Power Electronics, (2016)

[12] Giampaolo Buticchi, Davide Barater, Emilio Lorenzani, Carlo Concari, and Giovanni Franceschini, "A NineLevel Grid-Connected Converter Topology for SinglePhase Transformerless PV Systems" IEEE Transactions on Industrial Electronics, Vol. 61, No. 8, August 2014.

[13] Carmaline Joel Anthony, S. Gotekar, S.P.Muley, "Single phase transformerless grid connected PV inverter: A Review" International Journal on recent and innovation trends in computing and communication" Vol.4, Issue.5.

[14] Zameer Ahmad, S.N. Singh, "An improved single phase transformerless invertertopology for grid connected $P V$ system with reduce leakage current and reactive power capability” Elsevier (2017) Solar Energy 157 (2017) 133-146

[15] Sanjay Kumar Soren, Electrical Engineering 
Vol. 6 , No. 10, 2021, PP. 119 - 124

International Journal of Innovations in Engineering and Science, www.ijies.net

Department, National Institute of Technology, Rourkela "Single Phase Grid Connected Pv System" May 2014

[16] Kamran Zeb, Waqar Uddin, Muhammad Adil Khan, Zunaib Ali, Muhammad Umair Ali, Nicholas Christofides, H.J. Kim, “A comprehensive review on inverter topologies and control strategies for grid connected photovoltaic system" Elsevier (2018) Renewable and Sustainable Energy Reviews 94 (2018). 